\title{
Visualization of Automated Material Handling System Components in Semiconductor Industry over the Lifecycle
}

\author{
Patrick Boden ${ }^{1}$, Sebastian Rank ${ }^{1(\bowtie)}$, Thorsten Schmidt ${ }^{1}$, \\ and Martin Däumler ${ }^{2}$ \\ ${ }^{1}$ Chair of Material Handling and Logistics Engineering, TU Dresden, \\ Dresden, Germany \\ \{patrick.boden, sebastian.rank\}@tu-dresden.de \\ ${ }^{2}$ Fabmatics GmbH, Dresden, Germany
}

\begin{abstract}
Automated Material Handling Systems are highly complex which makes planning, monitoring and optimization a challenging task. Operators of an Automated Material Handling System (AMHS) have access to extensive data from the real system and additional data sources like material flow simulation studies. Until now, these data have mainly been evaluated statically in the form of predefined diagrams and reports. The aim of this article is to present a concept that allows interactive data visualization of semiconductor transport systems from planning up to their operational phase. Thereby the application of approaches from the field of Visual Analytics is of special interest. A high potential for a better understanding of the highly complex AMHS is seen here.
\end{abstract}

Keywords: AMHS $\cdot$ Lifecycle $\cdot$ Data visualization $\cdot$ Visual analytics

\section{Motivation}

Planning, monitoring and optimizing an Automated Material Handling System (AMHS) is highly challenging. Due to the diversity of the production equipment and their arrangement, efficient handling of logistical processes is of great importance. In order not to risk the production schedule high throughputs and short delivery times need to be achieved. To meet these requirements, AMHS have been established in $300 \mathrm{~mm}$ frontend factories. Ceiling-mounted Overhead Hoist Transport (OHT) systems are the most common systems in that area (see Hammel, Schmidt and Schöps 2012), but also other systems like Automated Guided Vehicles (AGV), Rail Guided Vehicles (RGV) and Conveyors are used (see Geng 2005).

Operators of AMHS have access to extensive data from the real system and additional data sources like material flow simulation studies (see Schmaler et al. 2017) or technical monitoring systems (see Siegel, Zhakov, Zhu and Schmidt 2018). Up to now, these data has mainly been evaluated statically in the form of predefined diagrams 
and reports. They are often created by employees, such as IT experts or support staff, who are not deployed with the evaluation. This approach makes it difficult to react rapidly to current issues and delays necessary planning and optimization tasks, due to the delay of essential adjustments of reports.

The aim of this article is to present our concept "AMHSviz" which allows interactive data visualization of semiconductor transport systems from planning up to their operational phase. The concept should allow the use of data from typical AMHS sources and should be available for analysis by different stakeholders (e.g. operators, sustainers, shift leaders, engineers, and managers). Thereby the application of approaches from the field of visual analytics is of special interest.

\section{Related Work}

\subsection{Data Visualization and Visual Analytics}

As a result of progress in information technology operators of technical systems, such as transport systems, increasingly have access to large amounts of raw data for the analysis of system states. Data streams from different sources are often linked so that they can be described as demanding in the dimensions volume, variety and velocity and hence as Big Data (see Fasel and Meier 2016). In such an environment data visualization is a powerful but also challenging technique to explore data sets and communicate findings (see Keim, Qu and Ma 2013). A new trend towards visual analytics focuses mainly on the interaction- and algorithm-based exploration of large data sets. A high potential for a better understanding of the highly complex AMHS is seen here.

Data Visualization. Data visualization can be defined as "the representation and presentation of data to facilitate understanding" (see Kirk 2016). This definition already indicates the importance of data acquisition and preparation as preliminary stages of the final visualization. This aspect is reflected in the process model for the visualization of data from Fry (2004, see Table 1). In seven steps, the process of data visualization is described, whereby steps one to four are dedicated to the area of data processing and the remaining steps can be dedicated to the visualization itself. In the last step of the model the possibility of interaction is mentioned to give the user the possibility to control and explore the underlying data. In order to achieve visualization, it is necessary to go through the individual steps. In each step methods like from the field of statistics are selected manually. This makes classical data visualization a rather static procedure, which complicates the dynamic exploration of complex data structures. 
Table 1. Process model for data visualization (based on Fry 2004)

\begin{tabular}{|c|c|c|}
\hline Step & Subject matter & Related field \\
\hline $\begin{array}{l}\text { (1) acquire } \\
\text { (2) parse }\end{array}$ & $\begin{array}{l}\text { - The matter of obtaining the data } \\
\text { - Providing some structure around what the } \\
\text { data means and ordering it into categories }\end{array}$ & computer science \\
\hline $\begin{array}{l}\text { (3) filter } \\
\text { (4) mine }\end{array}$ & $\begin{array}{l}\text { - Removing all but the data of interest } \\
\text { - The application of methods from statistics or } \\
\text { data mining, as a way to discern patterns or } \\
\text { place the data in mathematical context }\end{array}$ & $\begin{array}{l}\text { mathematics, statistics and } \\
\text { data mining }\end{array}$ \\
\hline $\begin{array}{l}\text { (5) represent } \\
\text { (6) refine }\end{array}$ & $\begin{array}{l}\text { - Determination of a simple representation, } \\
\text { whether the data takes one of many shapes } \\
\text { such as a bar graph, list, or tree } \\
\text { - Improvements to the basic representation to } \\
\text { make it clearer and more visually engaging }\end{array}$ & graphic design \\
\hline (7) interact & $\begin{array}{l}\text { - The addition of methods for manipulating } \\
\text { the data or controlling what features are } \\
\text { visible }\end{array}$ & $\begin{array}{l}\text { information visualization } \\
\text { and human computer } \\
\text { interface }\end{array}$ \\
\hline
\end{tabular}

Visual Analytics. In contrast to conventional visualization approaches, visual analytics allows a more dynamic analysis of the data. Collaborative work is made possible and thus the cooperation between the stakeholders of an AMHS can be improved. Visual analytics refers to techniques that automatically process data and present it in the form of interactive graphics (see Thomas and Cook 2005). Automatic data processing and the application of knowledge discovery algorithms are the central points of this approach (see Keim et al. 2008). Combined by interaction mechanisms this creates the possibility to react flexibly to operational and strategic questions and to use human abilities such as expert knowledge or human perception for the analysis (see Fig. 1). An analysis based on the visual analytics process is characterized by a constant change between visual interaction and automatic data processing.

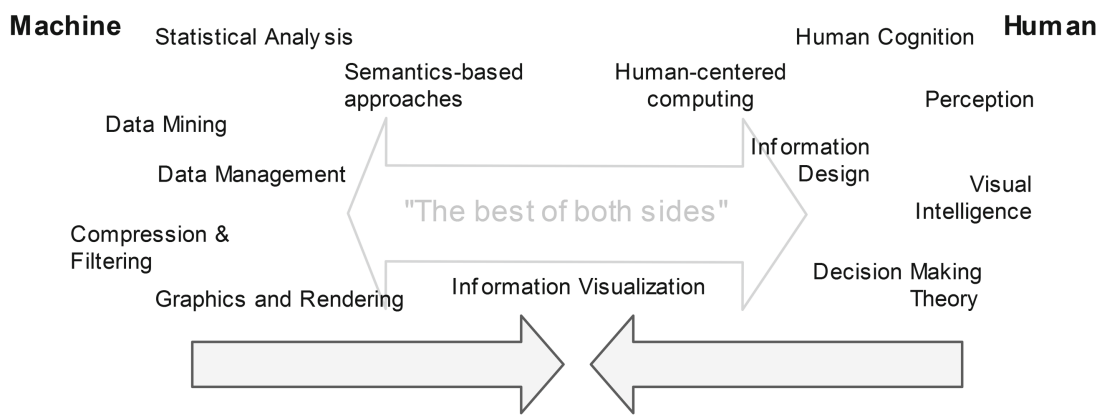

Fig. 1. Scientific disciplines integrated by visual analytics (Keim et al. 2008) 
By using this approach in the context of AMHS planning and operating, the visual exploration of system specific data should allow a better understanding of the system and its dynamics. Since the field of visual analytics is still under development there is no commercial software for the analysis of an AMHS available yet. As a first step, towards a visual analytics application, a software tool for data visualization shall be created which allows the connection of AMHS specific data sources and the design of interactive visualizations. In general, the data is captured automatically and pre-processed using basic algorithms like mean value calculation. Our aim is to implement high sophistic algorithms from the fields of data mining and statistical analysis at a subsequent stage to allow a more diverse analysis.

\subsection{AMHS Visualization}

For the visualization of AMHS performance and corresponding key figures, experts from practice and scientific literature mainly discuss established diagram types such as bar charts, box plots and line diagrams based on statistical data processing. Typical examples can be found in the contributions of Sokhan-Saj, Gaxiola, Mackulak and Malmgren (1999), Potoradi, Boon, Mason, Fowler and Michele (2002) or Hammel, Schmidt and Schöps (2012). For the location dependent visualization of data some authors also use heat maps (see Kortus, Däumler and Schmidt 2018). In this connection, Erler, Lübke, Loose and Hammel (2018) introduced a so called "real time monitor".

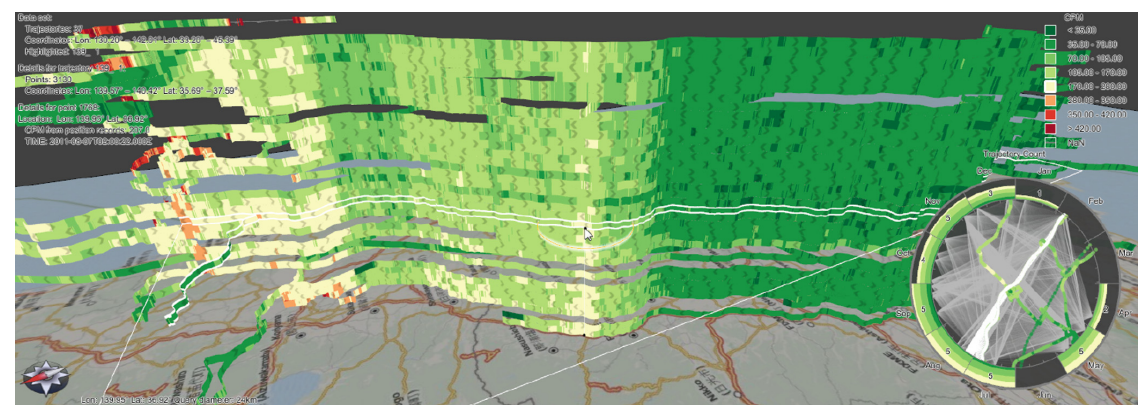

Fig. 2. Trajectory based visualization (Tominski, Schumann, Andrienko and Adrienko 2012)

The analysis of AMHS-specific literature reveals that novel, sophisticated visualization concepts such as the trajectory walls (see Fig. 2) or approaches from the field of visual analytics have not been established yet, even if necessary raw-data is available. In the semiconductor domain, data sources which provide information about transport orders, movement logs and error messages are the most important sources in order to judge about the condition of the AMHS. Furthermore the investigation of the AMHS vehicles, carriers and the remaining technical infrastructure are particularly objects of interest for a detailed analysis. Since AMHS typically have several hundred vehicles employed, the amount of data available is extensive. 
As AMHS are very complex and come along with a long life cycle, different user groups (as already mentioned, e.g. operators, sustainers, shift leaders, engineers and managers) are involved in the planning and control process. Thus different user roles with different views and demands on corresponding AMHS-data emerge. In consequence different visualization solutions in accordance to the users' needs are required. In this context expert interviews have been conducted and requirements for visualization solutions were identified (see Rank, Boden and Schneider 2018). Some of the most important findings are the low hardware requirements. Furthermore, visualization solutions should also be device independent and responsive. Based on these findings, the following section presents and discusses possible software tools.

\subsection{Visualization Software Tools}

The increasing importance of the subject data visualization can be seen in scientific literature (see Tam and Song 2016) as well as in the increasing use of advanced software such as QlikView or Tableau. Both tools allow interactive visualization as well as exploration and are common in semiconductor industry. Since it is rather unclear, if the capabilities of the tools meet all the requirements of the mentioned user groups a systematic evaluation becomes necessary. This is particularly true because the variety of available software in the field of visualization is large and the tools have a different focus.

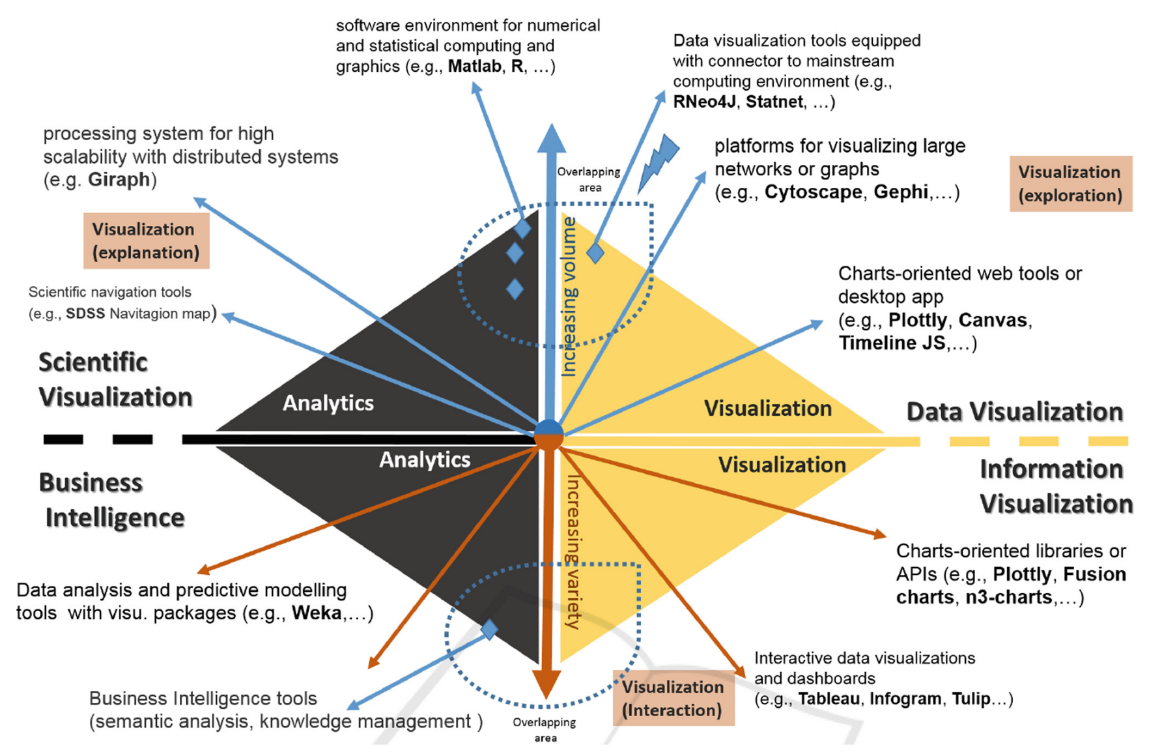

Fig. 3. Big Data visualization tools (Caldarola and Rinaldi 2017)

One possible option of such a taxonomy is illustrated by Caldarola and Rinaldi (2017, see Fig. 4). As a result, the software solutions investigated by the authors on the 
one hand differ in respect to their functional scope in the areas of analytics and visualization (x-axis). On the other hand, the software can be divided in accordance to the nature of the data that can be processed with the application. The applications are assigned on the basis of the data properties volume and variety (y-axis). Applications from the field of visual analytics can be assigned to the overlapping area along the variety axis. Due to this systematization, it is possible, to distinguish applications with extensive functions in the area of statistics (e.g. R) from applications with a clear focus in the design of interactive graphics (e.g. Tableau).

In their analysis, Caldarola and Rinaldi (2017) evaluated a variety of visualization solutions that can be used in the context of Big Data. Thereby, they not only focused on programs intended for end users, but also on software libraries that can be used by developers to create own illustrations and applications. The overview demonstrates a large variety of development tools and indicates that web-based applications are increasingly being developed. They can be used almost independently of an operating system. Typical visualization structures of web-based applications are charts, graphs or maps. An excerpt from the evaluated applications is shown in Table 2.

According to Fig. 3 and Table 2 most of the commercial visualizations tools (e.g. Tableau) are easy to use. They have a user-friendly user interface and they allow fast plot/graph generation and saving by simply clicking. On the other hand, they are restricted in terms of designing and defining new, highly sophisticated and selfdesigned plots. There are tools/libraries which focus on visualization and there are tools/libraries focusing on analytics. Apart from R, which has some major downsides in respect to plot interaction, none of the assessed tools show major strengths in both categories.

Table 2. Excerpt of the visualization tool survey (based on Caldarola and Rinaldi 2017)

\begin{tabular}{l|l|l|l|l|l}
\hline Name & Usage & $\begin{array}{l}\text { Software } \\
\text { category }\end{array}$ & $\begin{array}{l}\text { Visualization } \\
\text { structure }\end{array}$ & $\begin{array}{l}\text { Operating } \\
\text { system }\end{array}$ & License \\
\hline Tableau & Presentation & $\begin{array}{l}\text { Desktop } \\
\text { application }\end{array}$ & $\begin{array}{l}\text { Chart, graph, } \\
\text { map, etc. }\end{array}$ & $\begin{array}{l}\text { Windows, } \\
\text { OSX }\end{array}$ & Commercial \\
\hline Infogram & Presentation & $\begin{array}{l}\text { Desktop } \\
\text { application }\end{array}$ & $\begin{array}{l}\text { Chart, map, } \\
\text { image and } \\
\text { video }\end{array}$ & $\begin{array}{l}\text { Windows, } \\
\text { OSX }\end{array}$ & Commercial \\
\hline Plotly & $\begin{array}{l}\text { Presentation, } \\
\text { developers }\end{array}$ & $\begin{array}{l}\text { Web tool, } \\
\text { JavaScript } \\
\text { and Python } \\
\text { library }\end{array}$ & $\begin{array}{l}\text { Chart, plot, } \\
\text { map }\end{array}$ & $\begin{array}{l}\text { Web- } \\
\text { based }\end{array}$ & $\begin{array}{l}\text { Commercial, } \\
\text { community }\end{array}$ \\
\hline D3.js & Developers & $\begin{array}{l}\text { JavaScript } \\
\text { library }\end{array}$ & Chart, map & $\begin{array}{l}\text { Web- } \\
\text { based }\end{array}$ & Open source \\
\hline Chart.js & Developers & $\begin{array}{l}\text { JavaScript } \\
\text { library }\end{array}$ & Chart & $\begin{array}{l}\text { Web- } \\
\text { based }\end{array}$ & Open source \\
\hline
\end{tabular}


Related to the results of Rank, Boden and Schneider (2018) none of the available tools meets the evaluated requirements. In order to avoid limitations of commercial software solutions (e.g. limited extensibility), the development of an own application called "AMHSviz" was initiated. It will be discussed in detail in the next section "Description of the Software Demonstrator".

For the implementation of visualizations and interaction mechanisms the software library Plotly was chosen for AMHSviz. Plotly enables the integration of a wide variety of display formats and interaction possibilities. In order to guarantee the integration of highly specialized diagram types (such as trajectory walls) also other libraries can be integrated. The overall application is based on the frameworks Cordova and Electron. A detailed description of the application and its structure can be found in Däumler, Reith, Hochholzer and Schmidt (2018).

\section{Description of the Software Demonstrator "AMHSviz"}

A first result of the discussion in the sections before is the mentioned tool AMHSviz. It is an extension of a software tool based on the work of Däumler, Reith, Hochholzer and Schmidt (2018). They dealt with the analysis of simulation data of AMHS systems. In addition to the previous work, a possibility for the analysis of data from a real transport system was integrated. For this purpose, established AMHS data sources and possible interfaces were investigated. The data exchange between AMHSviz and the corresponding/dynamic databases can be done statically via database excerpts or log files, as well as continuously via the data exchange format JSON. The data is collected in a central data server and then processed by the visualization component into interactive graphics (see Fig. 5).

For data presentation, the AMHSviz allows the integration of various visualization types customized to the concrete application case. To meet the most important needs, the creation of reusable and stakeholder specific dashboards is possible (see Fig. 4) and first diagram types and interaction techniques were implemented. So far, graphic types such as radar plot, scatter plot or parallel coordinates can be used. The graphics allow different ways of interaction. For example, filters can be set or additional information can be displayed by hovering. As a result, the essential stakeholder requirements for a versatile and interactive visualization can be fulfilled.

The whole concept and a first demonstrator of AMHSviz were tested by applying AMHS-data. For this purpose, data from log files and the Murata AMHS Control System were automatically processed using an own implemented data wrapper. Investigating single vehicles or carrier categories (e.g. test or development) proved to be particularly informative and led, for example, to the identification of inefficient transport flows. 


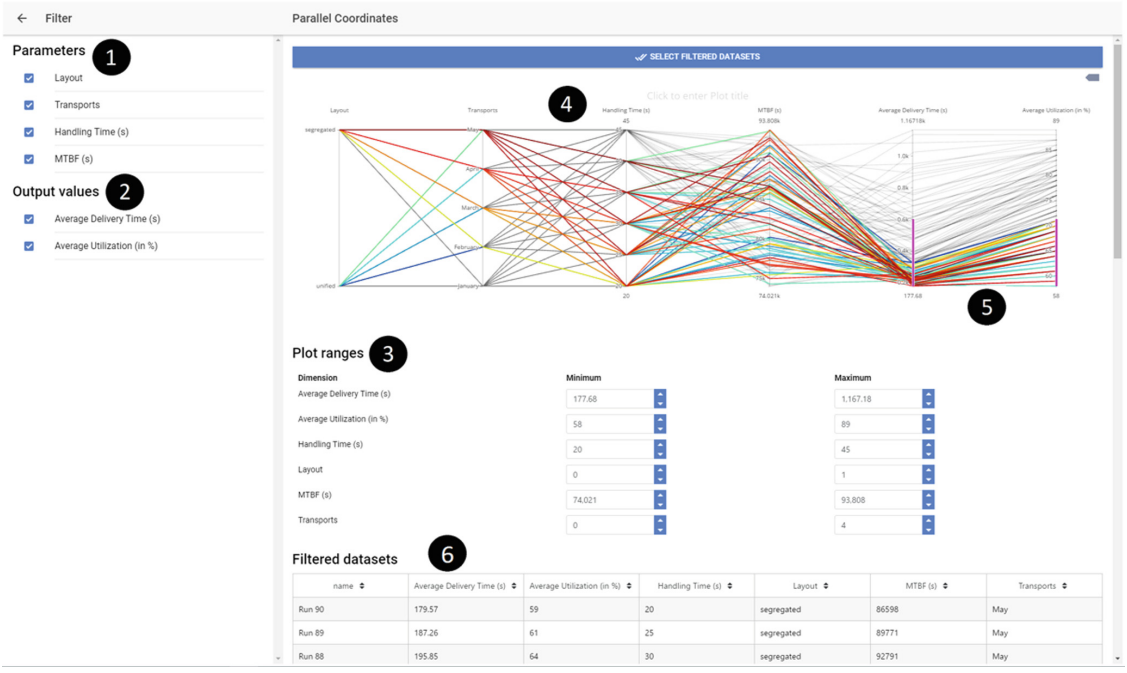

Fig. 4. AMHSviz-Screenshot of the user interface with (1) Selection of input parameters of interest (2) Selection of output values of interest (3) range selection for each axis (4) Parallel coordinates plot of the different data; color adjusted according to the order of the axes and the values on the axes (5) Manual interval selection [pinkish bars] of data according to values of the last two axes (6) List of selected runs (only a part is shown) (Däumler, Reith, Hochholzer and Schmidt 2018).

\section{Discussion/Implications}

This article describes the related work for the visualization of AMHS related data in the semiconductor environment. Typical AMHS data visualizations, possible software tools and relevant data sources were investigated. Dealing with the high diversity of stakeholders could be identified as an essential requirement for a visualization tool. Due to the high complexity of AMHS and the long life cycle, many people are engaged by the analysis of data. Through the application of concepts from the field of visual analytics, a promising way for the presentation of data and the interactive communication of results is seen. So far such a AMHS specific visualization tool does not exist.

A workflow/concept using an expanded software framework that allows evaluating extensive data collected from AMHS was developed-so called AMHSviz. Approaches from the field of visual analytics were integrated. AMHSviz provides a suitable possibility for different users ("roles") to react flexibly to operative and strategic questions over the life cycle of the system and to employ data from different sources.

Data that can be used for the analysis of transport systems have a strong timeand/or location-related character. One possibility for the further development of AMHSviz is the integration of data visualization approaches that enable a better 
analysis of such data. A comprehensive overview of visualization techniques especially for time-based data can be found at Aigner, Miksch, Schumann and Tominski (2011).

While comparatively simple algorithms for statistical analysis (e.g. calculation of mean values) have been implemented in the current demonstrator of AMHSviz, the integration of more sophisticated algorithms is planned for further development. In particular approaches from the field of data mining (such as cluster or sequence analysis) are to be examined for their suitability for the AMHS application case. In contrast to the algorithms implemented so far a more diverse analysis is aimed to better understand the connection between different system states. For example, the relationship between anomalies (such as traffic jams and technical disturbances) and the delivery time behavior could be investigated in more detail by customized data analysis and visualizations.

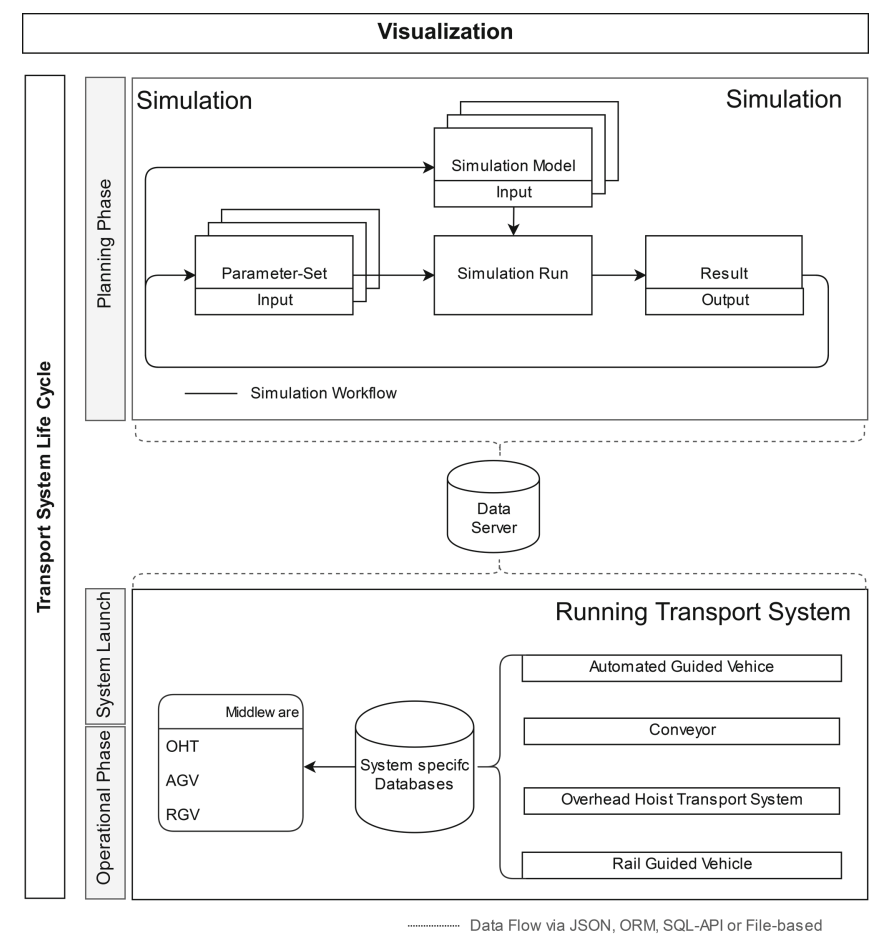

Fig. 5. Lifecycle visualization concept for AMHS (based on Däumler, Reith, Hochholzer and Schmidt 2018)

\section{References}

Aigner, W., Miksch, S., Schumann, H., Tominski, C.: Visualization of Time-Oriented Data. Springer, London (2011) 
Caldarola, E., Rinaldi, A.: Big data visualization tools: a survey - the new paradigms, methodologies and tools for large data sets visualization. In: 6th International Conference on Data Science, Technology and Applications, pp. 296-305 (2017)

Däumler, M., Reith, K.-B., Hochholzer, S., Schmidt, T.: Approach on evaluating material handling simulation runs under consideration of different target groups. In: ASIM Symposium Simulationstechnik (2018)

Erler, M., Lübke, J., Loose, L., Hammel, C.: AMHS real-time monitor. In: 18th European Advanced Process Control and Manufacturing Conference (APC|M) (2018)

Fasel, D., Meier, A.: Big Data: Grundlagen, Systeme und Nutzungspotenziale. Springer, Wiesbaden (2016)

Fry, B.: Computational Information Design. Doctoral thesis. Massachusetts Institute of Technology, Cambridge (2004)

Geng, H.: Semiconductor Manufacturing Handbook. McGraw Hill Professional, New York (2005)

Hammel, C., Schmidt, T., Schöps, M.: Network optimization prior to dynamic simulation of AMHS. In: Proceedings of the 2012 Winter Simulation Conference, 1956-1966 (2012)

Keim, D., Andrienko, G., Fekete, J.-D., Görg, C., Kohlhammer, J., et al.: Visual analytics: definition, process and challenges. In: Information Visualization - Human-Centered Issues and Perspectives, pp. 154-175 (2008)

Keim, D., Qu, H., Ma, K.-L.: Big-data visualization. IEEE Comput. Graph. Appl. 33, 20-21 (2013)

Kirk, A.: Data Visualisation: A Handbook for Data Driven Design, 1 edn. SAGE Publications Ltd., London (2016)

Kortus, G., Däumler, M., Schmidt, T.: Applying the Discrete Network Design Problem (DNDP) for designing AMHS layouts in semiconductor fabs. In: 29th Annual SEMI Advanced Semiconductor Manufacturing Conference (ASMC), pp. 295-300 (2018)

Potoradi, J., Boon, O.S., Mason, S., Fowler, J., Michele, P.: Using simulation-based scheduling to maximize demand fulfillment in a semiconductor assembly facility. In: Proceedings of the 2002 Winter Simulation Conference, pp. 1857-1861 (2002)

Rank, S., Boden, P., Schneider, G.: Integrated Development 4.0: State of the art of visualization systems in semiconductor industry. ECSEL JU, Dresden (2018)

Schmaler, R., Hammel, C., Schmidt, T., Schoeps, M., Luebka, J., Hupfer, R.: Strategies to empower existing automated material handling systems to rising requirements. IEEE Trans. Semiconductor Manuf. 30(4), 440-447 (2017)

Siegel, A., Zhakov, A., Zhu, H., Schmidt, T.: Trailer based rail monitoring in overhead hoist transport systems. In: 2018 International Symposium on Semiconductor Manufacturing (ISSM), pp. 1-4 (2018)

Sokhan-Saj, S., Gaxiola, G., Mackulak, G., Malmgren, F.: A comparison of the exponential and the hyperexponential distributions for modeling of move requests in a semiconductor fab. In: Proceedings of the 1999 Winter Simulation Conference, pp. 774-778 (1999)

Tam, N.T., Song, I.: Big data visualization: application in visualizing learning activities. In: Information Science and Applications (ICISA), pp. 399-408 (2016)

Thomas, J., Cook, K.: Illuminating the Path: A Research and Development Agenda for Visual Analytics. IEEE Press (2005)

Tominski, C., Schumann, H., Andrienko, G., Adrienko, N.: Stacking-based visualization of trajectory attribute data. IEEE Trans. Vis. Comput. Graph. 18(12), 2565-2574 (2012) 
Open Access This chapter is licensed under the terms of the Creative Commons Attribution 4.0 International License (http://creativecommons.org/licenses/by/4.0/), which permits use, sharing, adaptation, distribution and reproduction in any medium or format, as long as you give appropriate credit to the original author(s) and the source, provide a link to the Creative Commons license and indicate if changes were made.

The images or other third party material in this chapter are included in the chapter's Creative Commons license, unless indicated otherwise in a credit line to the material. If material is not included in the chapter's Creative Commons license and your intended use is not permitted by statutory regulation or exceeds the permitted use, you will need to obtain permission directly from the copyright holder. 